\title{
Developing Scenarios for Robot Assisted Play
}

\author{
Ben Robins, Ester Ferrari, Kerstin Dautenhahn
}

\begin{abstract}
This paper describes the user-centred development of play scenarios for robot assisted play, as part of the IROMEC project that develops a novel robotic toy for children with special needs. The project investigates how robotic toys can become social mediators, encouraging children with special needs to discover a range of play styles, from solitary to collaborative play (with peers, carers/teachers, parents etc). This paper presents the developmental process of constructing relevant play scenarios for children with different special needs. This process is driven by a) a comprehensive literature review that is related to play activities of children from different target user groups with existing technology, consultation with panel of experts (therapist, teachers, parents) and $b)$ by the result of experimental investigations of user requirements in trials with children with special needs. An important step (reported here) towards the development of the final play scenarios is the development of Outline Play Scenarios - a set of abstract scenarios that reflect the users' requirements and which are not related to any specific technological solution. The general methodological approach, as well as the outline play scenarios, may benefit the development of scenarios for other human-robot interaction research in robot assisted play and related areas. In future, these outline scenarios will be further developed to reflect and utilise the specific functionalities to be implemented in the new IROMEC robot and its different modules.
\end{abstract}

\section{INTRODUCTION}

Trest $\mathrm{n}$ recent years various robotic systems have been used in research to mediate interaction for people with and without cognitive and/or physical impairments. Life-like robots, e.g. artificial pets such as the baby seal Paro, the teddy bear Huggable [1-4], and humanoid robots such as the robotic doll Robota and the child-like Kaspar [5-9] were used to engage people in personal experience. Most of these robots, when built, focused on the technological innovation aspects. User needs, requirements, and scenarios of how to use the robots in concrete applications are often only considered at a later stage. The work described in this paper takes an alternative view, involving users from the very beginning of the robot design process. An important step towards the design of a novel robot is the development of scenarios, a process that this paper focuses on.

The work presented in this paper is part of the European project IROMEC, that develops a novel robotic toy for

The work described in this paper is conducted within the EU project IROMEC (Interactive Robotic Social Mediators as Companions) and was co-funded by the European Commission in the 6th Framework Programme under contract IST-FP6-045356.

B. Robins, E. Ferrari and K. Dautenhahn are with the Adaptive Systems Research Group. School of Computer Science, University of Hertfordshire, UK. (email: \{b.robins, e.ferrari, k.dautenhahn\} @ herts.ac.uk) children with special needs. Although the project recognizes the importance of the impact of technology on its users, the approach taken is based on ongoing consultations with panels of expert users (i.e teachers, therapists, parents) throughout the design and development stages in order to develop a robotic system that will meet specific needs of various target user groups.

The project recognizes the important role of play in child development and targets children who are prevented from or inhibited in playing, either due to cognitive, developmental, or physical impairment. The project investigates how robotic toys can become social mediators, encouraging children with special needs to discover a range of play styles, from solitary to social and cooperative play (with peers, carers/teachers, parents etc).

\section{SCENARIOS FOR ROBOT ASSISTED PLAY}

In the field of human-computer interaction, scenarios have been used as tools in various stages of system development, from problem definition to envisioning solutions, helping all stake holders to contribute to the analysis, design and evaluation of systems. Carroll [10] described scenario-based design as 'a family of techniques', describing the use of future systems at early points in their development. They can be in the form of textual narratives describing an activity in its context, video mock-ups, storyboards of annotated cartoon panels or physical situations that contrive to support certain user activities. Designers have long used scenarios to organize, justify, and communicate ideas. Scenarios are being used as vocabulary aids that are accessible to the users so they (the users) can be involved in the design process and help to define the technology they will use. Scenarios serve as central representations throughout development cycles, first describing the goals and concerns of current use, and then being successively transformed and refined through iterative design and evaluation processes [11].

In the IROMEC project we have adopted the concept of scenarios and used it for an additional purpose. Here, scenarios are seen as higher-level conceptualizations of the 'use of the robot in a particular context'. Scenarios are used not only as intermediary steps or tools in the design and development process of the robot, but more importantly, as play contexts which allow users to evaluate specifically implemented functionalities of the final outcome of the project, i.e. the IROMEC robot. 


\section{A. Target user-groups}

The IROMEC project targets children who are prevented from playing, either due to cognitive, developmental, or physical impairments or due to medical conditions.

With the aim to develop scenarios that are suitable for children with different types and grade of disability, the target user group has been divided into three main categories: children with cognitive impairments (such as autism), children with physical impairments (such as Muscular Dystrophy, Cerebral Palsy, bed restricted and hospitalized stay), and children with a combination of both.

\section{B. Type of play}

Numerous types of play have been identified in the literature (an in-depth review can be found in [12]). In the context of the project for the development of play scenarios we refer to the following types of play:

1) Sensory motor play: it consists of simple repetitive muscle movements with or without objects (e.g. repetitive motor movements). This activity is done merely for the enjoyment of the physical sensation it produces [13, 14].

2) Symbolic play: during symbolic play children can differentiate fantasy from reality. They substitute one object for another, and act toward them as if they were these other objects [14]. Play is no longer constrained by an object's physical proprieties [15].

3) Constructive play: is the manipulation of objects for the purpose of constructing or creating something [14]. As well, construction may manifest itself as teaching another how to do something [13].

4) Games with rules: the child accepts rules, adjusts to them and controls his actions and reactions within the given limits [13]. The child and/or their playmate(s) may decide the rules of the game.

We consider that play evolves through different stages but the transition between them need not be linear (e.g. a child can move from sensory motor play to constructive play without passing through symbolic play).

\section{Scenarios' building blocks}

Scenarios, as stated above, are seen as higher-level conceptualisations of the 'use of the robot in a particular context'. A unified structure of the scenarios was adopted and modified from the scenario-based design methodology $[10,16]$ and is described in Table I.

TABLE I

SCENARIOS' STRUCTURE

\begin{tabular}{|c|c|}
\hline $\begin{array}{l}\text { Actors/ } \\
\text { Roles }\end{array}$ & $\begin{array}{l}\text { This identifies the roles of the different actors involved } \\
\text { (children, therapists, parents...) highlighting the relationships } \\
\text { among them. How are they involved in the activity? Is it } \\
\text { appealing to all the participants? }\end{array}$ \\
\hline $\begin{array}{l}\text { Type of } \\
\text { play }\end{array}$ & $\begin{array}{l}\text { Is the activity a sensory motor play, and/or a symbolic play, } \\
\text { and/or a constructive play, and/or a game with rules? }\end{array}$ \\
\hline $\begin{array}{l}\text { Activity } \\
\text { description }\end{array}$ & $\begin{array}{l}\text { Description of what happens as the activity is carried out. } \\
\text { This points out the objectives of the different users who are } \\
\text { taking part in the activity. }\end{array}$ \\
\hline $\begin{array}{l}\text { Activity } \\
\text { model }\end{array}$ & $\begin{array}{l}\text { Can the activity be simplified into an identifiable set of } \\
\text { phases? This also highlights recursive passages and } \\
\text { sequences. }\end{array}$ \\
\hline $\begin{array}{l}\text { Place/ } \\
\text { Setting }\end{array}$ & $\begin{array}{l}\text { Description of the characteristics of the physical or virtual } \\
\text { context, including the environmental qualities, the space } \\
\text { organization, and the morphology. Is the location of the } \\
\text { activity affecting what is going on or is it irrelevant? }\end{array}$ \\
\hline $\begin{array}{c}\text { Artifacts/ } \\
\text { media }\end{array}$ & Tools that are supporting the activity. \\
\hline $\begin{array}{l}\text { Time/ } \\
\text { Flow }\end{array}$ & $\begin{array}{l}\text { Which is the average duration of the activity? Is duration } \\
\text { critical? Is the activity following a schedule? Does it repeat } \\
\text { over time? Is it following a rhythm or a recursive pattern? }\end{array}$ \\
\hline Keywords & $\begin{array}{l}\text { Highlights of values of the activity with respect to the actors } \\
\text { involved. }\end{array}$ \\
\hline
\end{tabular}

\section{THE DEVELOPMENTAL PROCESS OF PLAY SCENARIOS}

Fig 1 shows the process adopted in the IROMEC project of developing play scenarios, from building preliminary concepts for play scenarios, through the formation of outline scenarios for robot assisted play, to the completion of scenarios for robot assisted play and robotic mediators.

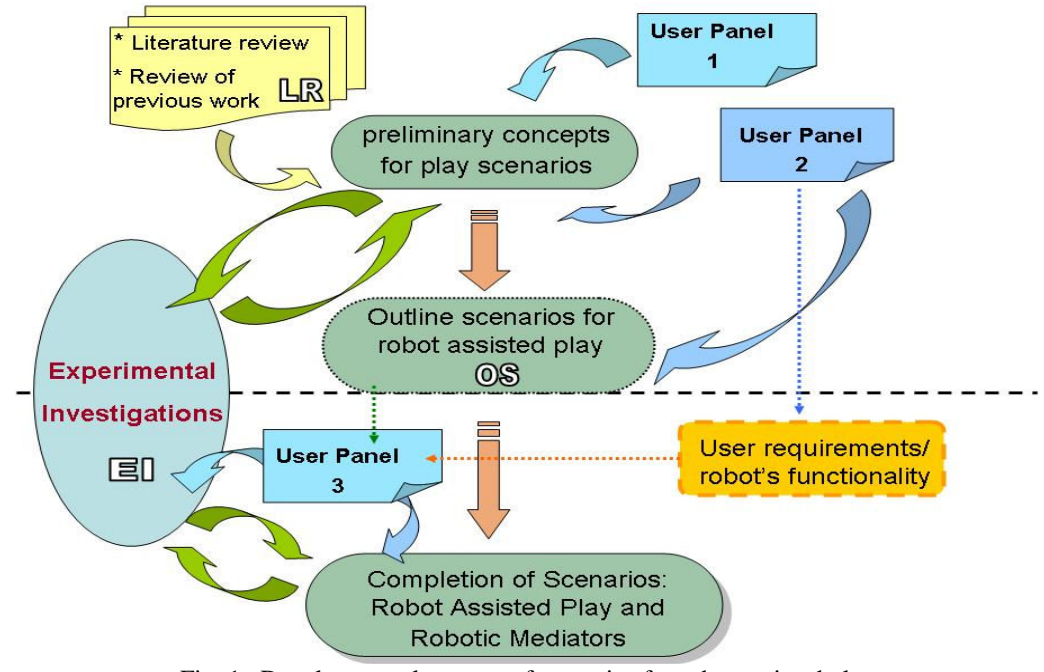

Fig. 1. Developmental process of scenarios for robot assisted play 
The process uses the following three intermediary sets of scenarios in various stages, leading to the development of the final core scenarios for robot assisted play and robotic mediators:

- scenarios derived from literature review prefixed 'LR'

- scenarios used in experimental investigations of user requirements - prefixed 'EI'

- $\quad$ high level outline play scenarios - prefixed 'OS'.

The preliminary concepts for play scenarios are based on the literature review as well as experimental investigations and are related to existing technology used in play activities by the various target user-groups. The results from the experimental investigation of various concepts of play scenarios together with outcome of the consultation with the panel of experts users (different panels of teachers, therapists, parents related to the different target user-groups) are then merged to form the Outline Play Scenarios that reflect the user requirements and are not related to any specific technological solution/robot.

During the next phase of the project, these scenarios will further be developed, in order to reflect and utilise the specific functionalities to be implemented in the IROMEC robot and its various modules. It will take into account results of ongoing experimental investigations of the different functionalities of the IROMEC robot which will be carried out with the different target user groups as well as further consultations with user panels, to form the core set of scenarios for robot assisted play and robotic mediators.

\section{A. Literature Review and Users Panels}

In order to understand the play needs of the user groups, and to investigate how robotic toys could be used as a play tool to assist in the children's development, a comprehensive literature review related to play activities of children from different target user groups using existing technology has been carried out. The review resulted in preliminary play scenarios of children with various special needs playing with a wide range of animated, lifelike robotic systems as well as mobile or modular systems (see table II). These preliminary scenarios provided important information regarding play activities, limitations, needs, and the range of interactions that computer or robotic devices can facilitate, thus providing important inspiration to the concept generation of the IROMEC systems, and highlighted important aspects to be considered in the development of play scenarios.

In addition, several panels of experts were organized by the project partners in various European countries, in order to collect important information related to the play activity of children with special needs, cf. [52] for details.
The panels involved professionals from different special education schools, teachers, therapists (e.g. psychotherapists, speech therapists, play therapists, physiotherapists, occupational therapists), as well as parents and family members.

TABLE II

LITERATURE REVIEW PROVIDING INTERMIDIARY SET OF PLAY SCENARIOS

\begin{tabular}{|c|c|c|c|c|c|c|c|}
\hline \multirow{2}{*}{ References } & \multirow{2}{*}{ 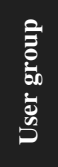 } & \multicolumn{4}{|c|}{ Play Type } & \multirow{2}{*}{ 逽 } & \multirow{2}{*}{ 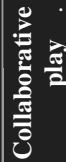 } \\
\hline & & $\begin{array}{l}\overline{\mathbf{S}} \\
\mathbf{M}\end{array}$ & $\begin{array}{l}\overline{\mathbf{S}} \\
\mathbf{Y}\end{array}$ & $\begin{array}{l}\mathbf{C} \\
\mathbf{O}\end{array}$ & $\begin{array}{l}\mathbf{G} \\
\mathbf{R}\end{array}$ & & \\
\hline Blotcher \& Picard 2002 [17] & $\mathrm{AT}$ & $\checkmark$ & & & & $\checkmark$ & \\
\hline Weir \& Emanuel 1976 [18] & AT & $\checkmark$ & & & & $\checkmark$ & \\
\hline $\begin{array}{l}\text { Michaud \& Theberge-Turmel } \\
\text { 2002; Michaud et al } 2003 \text { [21- } \\
\text { 22] }\end{array}$ & AT & & & $\checkmark$ & & & \\
\hline Strickland 1996; $1998[19,20]$ & $\mathrm{AT}$ & $\checkmark$ & & & & $\checkmark$ & \\
\hline $\begin{array}{l}\text { Michaud \& Theberge-Turmel } \\
\text { 2002; Michaud et al } 2003 \text { [21- } \\
\text { 22] }\end{array}$ & AT & $\checkmark$ & & & & $\checkmark$ & \\
\hline $\begin{array}{l}\text { Duquette et al. 2006; Michaud et } \\
\text { al } 2007 \text { [23-25] }\end{array}$ & $\mathrm{AT}$ & $\checkmark$ & & & & $\checkmark$ & \\
\hline $\begin{array}{l}\text { Robins et al. 2005; Werry et al. } \\
\text { 2001; } 2002[9,26-30]\end{array}$ & AT & $\checkmark$ & & & & $\checkmark$ & $\checkmark$ \\
\hline $\begin{array}{l}\text { Dautenhahn \& Billard 2002; } \\
\text { Robins et al. 2004; 2005; Davis } \\
\text { et al. } 2005[5-9,31]\end{array}$ & AT & $\checkmark$ & & & $\checkmark$ & $\checkmark$ & $\checkmark$ \\
\hline Hornof \& Cavender 2005 [32] & PC & $\checkmark$ & & & & $\checkmark$ & \\
\hline Schulmeister et al. 2006 [34] & MI & $\checkmark$ & & & & & $\checkmark$ \\
\hline Cook et al. 2000; $2005[35,36]$ & MI & $\checkmark$ & & $\checkmark$ & & & $\checkmark$ \\
\hline Lathan \& Malley 2001[33] & $\mathrm{PC}$ & & $\checkmark$ & & & $\checkmark$ & \\
\hline Marti et al. $2005[2,3]$ & PC & $\checkmark$ & $\checkmark$ & & & $\checkmark$ & $\checkmark$ \\
\hline Stiehl et al. 2006 [4] & PC & $\checkmark$ & & & & $\checkmark$ & \\
\hline Kronreif et al. 2005 [37] & $\begin{array}{l}\text { TD } \\
\text { MI }\end{array}$ & & & $\checkmark$ & & $\checkmark$ & \\
\hline $\begin{array}{l}\text { Lund et al. 2004; Lund \& Marti } \\
2005[38,39]\end{array}$ & $\begin{array}{l}\text { TD } \\
\text { PC }\end{array}$ & & & $\checkmark$ & $\checkmark$ & & $\checkmark$ \\
\hline $\begin{array}{l}\text { Kozima 2004; Kozima et al. } \\
2005 \text { [40-42] }\end{array}$ & $\begin{array}{l}\text { TD } \\
\text { AT }\end{array}$ & $\checkmark$ & & & & $\checkmark$ & \\
\hline $\begin{array}{l}\text { Michaud \& Caron } 2002 \\
\text { [43] }\end{array}$ & $\begin{array}{l}\text { TD } \\
\text { AT } \\
\text { PC }\end{array}$ & $\checkmark$ & & & & $\checkmark$ & \\
\hline $\begin{array}{l}\text { Kozima et al. 2005; Kozima \& } \\
\text { Yano } 2001[41,44,45]\end{array}$ & $\begin{array}{l}\text { TD } \\
\text { AT }\end{array}$ & $\checkmark$ & & & & $\checkmark$ & $\checkmark$ \\
\hline Ackermann $2002[46]$ & TD & & $\checkmark$ & $\checkmark$ & & & $\checkmark$ \\
\hline Raffle et al. 2006 [47] & TD & & & $\checkmark$ & & & $\checkmark$ \\
\hline $\begin{array}{l}\text { Chioccariello et al. 2001; 2002; } \\
2004 \text { [48-50] }\end{array}$ & TD & & & $\checkmark$ & & & $\checkmark$ \\
\hline Marti et al. $2004[1]$ & TD & & $\checkmark$ & $\checkmark$ & & & $\checkmark$ \\
\hline Lund et al. 2005 [51] & TD & $\checkmark$ & & & $\checkmark$ & & $\checkmark$ \\
\hline Robins et al. 2007 [52] & TD & $\checkmark$ & & & & $\checkmark$ & $\checkmark$ \\
\hline $\begin{array}{l}\text { Legend } \\
\text { User group: AT: children with a } \\
\text { PC: children with ph } \\
\text { MI: children with mo } \\
\text { TD: typically develo }\end{array}$ & $\begin{array}{l}\text { sm or } \\
\text { ical a } \\
\text { r imp } \\
\text { d chil }\end{array}$ & $\begin{array}{l}\text { other } \\
\text { dd cog } \\
\text { airme } \\
\text { aren }\end{array}$ & iitiv & imped & rmen & $\begin{array}{l}\text { nents } \\
\text { ts } \\
\text { cted chil }\end{array}$ & ildren \\
\hline $\begin{array}{ll}\text { Play type } & \text { SM: sensory motor } \mathrm{p} \\
& \text { SY: symbolic play }\end{array}$ & & & & & e ple & & \\
\hline
\end{tabular}

The user panel meetings gave insights into the characteristics of the children's play: type of play (e.g. solitary play, playing alone but in parallel to others, collaborative play, etc), movement of child and toy in the play, the importance of imitation and turn-taking games with other interactors, and so on. The panel also provided 
input for design requirements related to familiarity, choice and controls, complexity and modularity, appearance, behaviour, environment and context.

\section{B. Experimental investigation of play scenarios}

Various aspects of the user requirements, as expressed in the user panel meetings, were implemented in experimental play scenarios and investigated in field trials using existing available technology. The results of these trials are documented in play scenarios that reflect the specific play activities. The field trials also highlighted important aspects for the robot design. This task is of an on-going nature in order to feed into both the design of interactions, and to the robot design, and helps to form the final scenarios for robot assisted play and robot mediators.

Two robots were used in the trials (one robot at a time):

a) KASPAR - a $60 \mathrm{~cm}$ high humanoid child-sized sitting robot developed by our research group at University of Hertfordshire (see figure 2 left, a more detailed description can be found at http://kaspar.feis.herts.ac.uk).

b) $L E G O R O B O T$ - a small mobile robot that was developed specifically for a simple turn-taking and sensory game for children with autism (see figure 2 right).

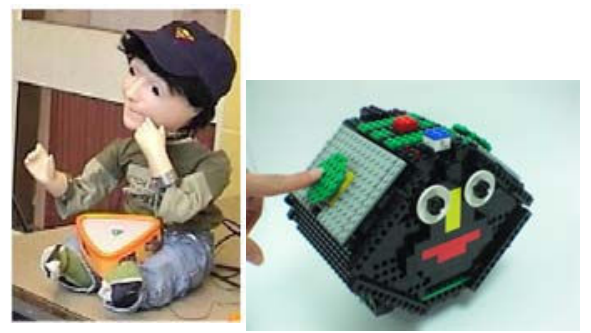

Fig. 2. The two robots that were used in the trials: Kaspar (left) and Legorobot (right).

The trials were designed to allow the children to have unconstrained interaction with the robots with a high degree of freedom, and to build a foundation for further possible interactions with peers and adults using the robot as a mediator $[6,7,17,18]$.

As stated above, the trials investigated various user requirements and were used as an aid to the main task of forming play scenarios for the IROMEC robot. Although a detailed description of these trials is beyond the scope of this paper, the following section presents two examples of play scenarios investigated in these trials:

\section{1) Example of an Experimental Investigation scenario} with the humanoid robot

In this scenario two children with autism are involved in a turn-taking and imitation game. The two children are seated in front of the humanoid robot (Kaspar) that is placed on a table. One child is controlling the robot (using a remote control) and the other is imitating the robot's behaviour (see fig. 3).

The objective of the scenario is to engage the children in an interactive play activity and in an imitation game where they are in control of the activity. These enable the actors to play together an imitation game (mediated by the robot).
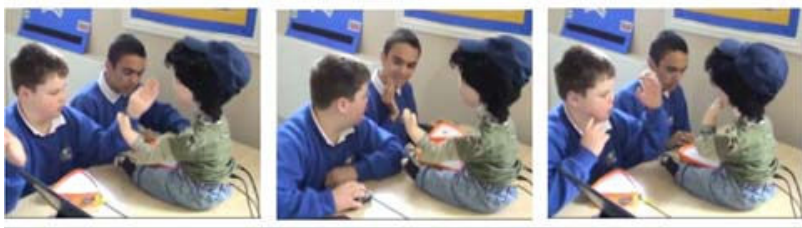

Fig. 3. Example of Experimental Investigation scenario of robot mediated interaction between peers (Kaspar).

The activity can be described as sequences of imitation phrases, where one child controls the robot and the other child imitates its movements. The game starts when the first child - operating the robot remotely - changes the robot's posture. The other child imitates the action. The leading child has to wait for the imitating child to imitate the robot correctly before moving to the next step (e.g. changing the robot's posture). After a few rounds, the children exchange roles.

\section{2) Example of an Experimental Investigation scenario} with a stationary inanimate robot

In this scenario two actors are involved in the game, a child and an adult. The adult has a supportive role - to respond to the child's initiative, or to take the initiative and encourage the child to play, when needed. As this is a very repetitive game, the adult needs also to introduce variation in the way the game is played (vocal sounds, tone of voice, etc).

The game is played using the stationary inanimate robot (Legorobot), and consists in a turn-taking game with a sensory reward. The robot is placed on the floor and the participants are sitting around it (see fig. 4). The objective of the game is to engage the child in a collaborative turn-taking game with another person, whilst having enjoyment and sensory rewards (lights) as a result.

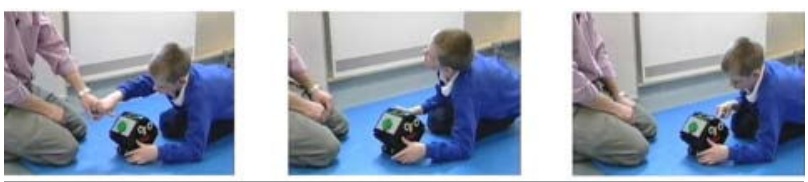

Fig. 4. Example of Experimental Investigation scenario of a turn-taking game with a sensory reward (Legorobot).

The game starts with repetitive actions to enable the turn taking (press one button and the red light goes on, press the other button, the red light goes off and a green light goes on), and is designed in a such a way that the buttons have to be pressed in turns, otherwise nothing 
happens. The repetitive actions are followed by something different and new (press the first button for the third time and a white flashing light goes on). Then the whole sequence can start again and can be repeated as many times as the participants like. In this specific experimental investigation, several variations can be introduced (e.g. sound can be introduced by each person calling out the colour of the light before it appears).

\section{Outline Scenarios for Robot Assisted Play}

As explained above, the preliminary concepts of play scenarios (scenarios derived from the literature review and scenarios used in the experimental investigations) helped to form the Outline Scenarios for Robot Assisted Play (Table III below).

TABLE III

OUTLINE SCENARIOS FOR ROBOT ASSISTED PLAY

\begin{tabular}{|c|c|c|c|c|c|c|c|c|}
\hline \multirow{2}{*}{$\begin{array}{l}\text { Scenario } \\
\text { (title and characterization) }\end{array}$} & \multirow{2}{*}{ 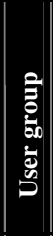 } & \multirow{2}{*}{ 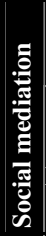 } & \multicolumn{4}{|c|}{ Play Type } & \multirow{2}{*}{ 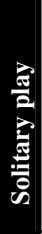 } & \multirow{2}{*}{ 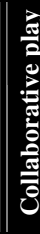 } \\
\hline & & & $\begin{array}{l}\mathbf{S} \\
\mathbf{M}\end{array}$ & $\mathbf{S}$ & $\begin{array}{l}\mathbf{C} \\
\mathbf{O}\end{array}$ & $\begin{array}{l}\mathbf{G} \\
\mathbf{R}\end{array}$ & & \\
\hline Turn taking - with a mobile robot & AT & $\mathbf{H}$ & $\checkmark$ & & & $\checkmark$ & & $\checkmark$ \\
\hline Push it - Cause \& effect, turn taking & AT & $\mathbf{H}$ & $\checkmark$ & & & $\checkmark$ & $\checkmark$ & $\checkmark$ \\
\hline Turn taking - for sensory reward & AT & $\mathbf{H}$ & $\checkmark$ & & & & & $\checkmark$ \\
\hline Imitation game - Imitation game & AT & $\mathbf{H}$ & $\checkmark$ & & & & & $\checkmark$ \\
\hline I am in control - Imitation game & AT & $\mathbf{H}$ & $\checkmark$ & & & & & $\checkmark$ \\
\hline Hide \& Seek - Spatial perception & PC & $\mathbf{M}$ & & & & $\checkmark$ & $\checkmark$ & $\checkmark$ \\
\hline Express yourself - Cause \& effect & $\mathrm{PC}$ & $\mathbf{L}$ & $\checkmark$ & & & & $\checkmark$ & $\checkmark$ \\
\hline Bring me the ball - Cause \& effect & PC & M & $\checkmark$ & & & & $\checkmark$ & $\checkmark$ \\
\hline $\begin{array}{l}\text { Musical sequence - Reproduce a } \\
\text { sequence }\end{array}$ & $\mathrm{PC}$ & $\mathbf{H}$ & & & & $\checkmark$ & $\checkmark$ & $\checkmark$ \\
\hline Follow-Me $-\mathrm{Be}$ in control & $\mathrm{PC}$ & $\mathbf{M}$ & $\checkmark$ & & $\checkmark$ & & $\checkmark$ & $\checkmark$ \\
\hline $\begin{array}{l}\text { Vibration - Sensory reward \& } \\
\text { stimulation }\end{array}$ & $\mathrm{PC}$ & $\mathbf{L}$ & $\checkmark$ & & & & $\checkmark$ & \\
\hline Make it move - Cause \& effect & $\mathrm{PC}$ & $\mathbf{M}$ & $\checkmark$ & & & & $\checkmark$ & $\checkmark$ \\
\hline $\begin{array}{l}\text { Catch me if you can - Planning \& } \\
\text { cooperation }\end{array}$ & $\mathrm{PC}$ & $\mathbf{H}$ & $\checkmark$ & & & $\checkmark$ & $\checkmark$ & $\checkmark$ \\
\hline Drawings - Expressiveness & $\mathrm{PC}$ & $\mathbf{H}$ & $\checkmark$ & $\checkmark$ & $\checkmark$ & & $\checkmark$ & $\checkmark$ \\
\hline Dance with me - Imitation & $\mathrm{PC}$ & $\mathbf{L}$ & $\checkmark$ & & $\checkmark$ & & $\checkmark$ & \\
\hline Find it! - Cause \& effect & PC & $\mathbf{M}$ & $\checkmark$ & & $\checkmark$ & & $\checkmark$ & $\checkmark$ \\
\hline Peek a boo - Explorative game & $\mathrm{PC}$ & $\mathbf{L}$ & $\checkmark$ & & & & $\checkmark$ & \\
\hline $\begin{array}{l}\text { Construct my own robot } \text {-Collaborative } \\
\& \text { constructive }\end{array}$ & $\mathrm{PC}$ & $\mathbf{H}$ & & & $\checkmark$ & & & $\checkmark$ \\
\hline $\begin{array}{l}\text { How do I feel? - Constructive \& } \\
\text { exploring emotion }\end{array}$ & $\mathrm{PC}$ & $\mathbf{H}$ & & $\checkmark$ & $\checkmark$ & & & $\checkmark$ \\
\hline Build a tower - Solitary \& constructive & MI & $\mathbf{L}$ & & & $\checkmark$ & & $\checkmark$ & \\
\hline Mirror emotions - Control expressions & MI & $\mathbf{L}$ & & $\checkmark$ & & & $\checkmark$ & \\
\hline My pet and me - Pretend play & MI & $\mathbf{L}$ & $\checkmark$ & $\checkmark$ & & & $\checkmark$ & \\
\hline Playing a character - Pretend play & MI & $\mathbf{H}$ & & $\checkmark$ & & & & $\checkmark$ \\
\hline Simulated board games - Board game & MI & $\mathbf{H}$ & & & & $\checkmark$ & & $\checkmark$ \\
\hline \multicolumn{9}{|c|}{ Legend } \\
\hline \multicolumn{9}{|c|}{$\begin{array}{l}\text { User group: AT: children with autism or other cognitive impairments } \\
\text { PC: children with physical and cognitive impairments } \\
\text { MI: children with motor impairments and bed restricted children }\end{array}$} \\
\hline \multicolumn{9}{|c|}{ Social mediation $\quad \mathrm{H}-$ high $\quad \mathrm{M}$-medium $\quad \mathrm{L}$ - low } \\
\hline $\begin{array}{ll}\text { Play type } & \text { SM: sensory motor play } \\
& \text { SY: symbolic play }\end{array}$ & $\begin{array}{l}\mathrm{CO} \\
\mathrm{GR}\end{array}$ & $\begin{array}{l}\text { con } \\
\text { gan }\end{array}$ & $\begin{array}{l}\text { nstruc } \\
\text { nes w }\end{array}$ & $\begin{array}{l}\text { ctive } \\
\text { Nith } 1\end{array}$ & $\begin{array}{l}\text { play } \\
\text { rules }\end{array}$ & & & \\
\hline
\end{tabular}

These are abstract scenarios that reflect the users' requirements and which are not restricted to any specific technological solution.

These outline play scenarios are on a high level of abstraction, neither are they limited to the implementation or availability of specific robots, nor do they rely on specific technology (e.g. specific actuators/sensors). For example, in a turn taking scenario with sensory rewards, the outline scenario does not specify the exact nature of the reward; it could be light, sound, movement, etc.

As stated above, these set of scenarios will further be developed, in consultation with the user panels, in order to derive a core set of final play scenarios which will give users from the different target user groups possible ways of interacting with the IROMEC robot using specific built-in functionality. A very important aspect of play scenarios is to encourage play between pairs of children whereby the robot can serve a mediator.

The table below is an example of an outline play scenario.

TABLE IV

EXAMPLE OF OUTLINE PLAY SCENARIO:

'TURN-TAKING FOR SENSORY REWARD'

\begin{tabular}{|c|c|}
\hline $\begin{array}{c}\text { Actors/ } \\
\text { Roles }\end{array}$ & $\begin{array}{l}\text { Two actors are involved in the game. These actors could be two } \\
\text { children, or a child and an adult (e.g. teacher, family member, } \\
\text { etc). When two children are playing the game, both actors have } \\
\text { equal roles. When an adult plays with the child, the adult has a } \\
\text { supportive role - to respond to the child's initiative, or to take } \\
\text { the initiative and encourage the child to play, when needed. }\end{array}$ \\
\hline Play Type & Sensory motor play, game with rules \\
\hline $\begin{array}{c}\text { Activity } \\
\text { description }\end{array}$ & $\begin{array}{l}\text { The game consists in a collaborative turn-taking activity with a } \\
\text { mobile robot. The mobile robot has a start/stop activation } \\
\text { mechanism that can be controlled by the user. } \\
\text { The objective of the game is to engage the child in a } \\
\text { collaborative turn-taking activity with another person (peer or } \\
\text { adult). The motivations of the child are threefold: } \\
\text { - the 'cause and effect' satisfaction and interest - i.e. when } \\
\text { activating the robot - the robot moves; } \\
\text { - the excitement of anticipation - waiting for the robot to reach } \\
\text { the person (peer or adult); } \\
\text { - engaging in a turn-taking game with another person. } \\
\text { The motivation of the adult is to encourage the child to have } \\
\text { social interaction in a collaborative play and also to respond to } \\
\text { the child's initiative when taken. }\end{array}$ \\
\hline $\begin{array}{c}\text { Activity } \\
\text { model }\end{array}$ & $\begin{array}{l}\text { Sitting on the floor at a distance from each other, one user aims } \\
\text { the robot towards the other user and activates the wheels of the } \\
\text { robot causing it to move toward the other player. When the } \\
\text { robot reaches the second player, they should stop the robot's } \\
\text { movement, turn it around, re-activate it, and send it back } \\
\text { towards the other player. This session can be repeated as many } \\
\text { times as the participants want. There could be several variations } \\
\text { of this activity, depending on the level of functionality } \\
\text { implemented in the robot (e.g. sensors to detect people, to } \\
\text { search, find and follow an object with specific colour, etc.). }\end{array}$ \\
\hline $\begin{array}{c}\text { Place/ } \\
\text { Setting }\end{array}$ & $\begin{array}{l}\text { The game is best played on the floor in a room with a large } \\
\text { empty space (although any floor space can be sufficient). Large } \\
\text { space can allow the participants to go to different points in the } \\
\text { room, or to run around and wait in anticipation for the robot to } \\
\text { reach them. }\end{array}$ \\
\hline $\begin{array}{l}\text { Artifacts/ } \\
\text { media }\end{array}$ & $\begin{array}{l}\text { A mobile robot with a start/stop user interface mechanism that } \\
\text { also includes status and sensory displays (light, sounds, etc.). }\end{array}$ \\
\hline $\begin{array}{l}\text { Time/ } \\
\text { Flow }\end{array}$ & $\begin{array}{l}\text { The game is made up of a short sequence of actions. This basic } \\
\text { phase can repeat itself many times, thus the duration of the } \\
\text { activity is unlimited and can take place as long as the } \\
\text { participants are interested. }\end{array}$ \\
\hline Keywords & $\begin{array}{l}\text { Turn-taking, enjoyment and excitement, social interaction } \\
\text { during collaborative play, cause and effect, anticipation. }\end{array}$ \\
\hline
\end{tabular}




\section{CONCLUSION}

By providing a robot-supported play environment where the robot serves as a social mediator, the IROMEC project aims to empower children with special needs to prevent dependency and isolation, helping them develop their potential and learn new skills.

The abilities, needs, and levels of development among the children in any given group vary significantly. As such, and regardless of any advanced technologies implemented in any robotic system, there cannot be a single 'general purpose robot' that will answer all the users' needs or facilitate all possible ways of interaction. This further reflects upon the importance of the approach taken in the IROMEC project which is based on ongoing consultations with panels of expert users (i.e teachers, therapists, parents) throughout the design and development stages. This paper reports on the development process of play scenarios for robot assisted play and a robotic mediator, utilizing the input from user panels and experimental investigations into the various stages of the development process in order to develop a novel robotic system that will consider specific needs of various target user groups. In the next step, the outline scenarios described in table III will further be developed, in order to reflect and utilise the specific functionalities to be implemented in the IROMEC robot and its various modules. They will be developed in consultation with the user panels, against specific therapeutic and educational objectives of the various IROMEC's target user groups.

This paper presented a user-centred methodology towards developing play scenarios for robot assisted play. The benefit of this work to researchers outside the IROMEC project is twofold: Firstly, the general approach of how to develop play scenarios for human-robot interaction is not limited to the specific user groups targeted in the IROMEC project and could be adopted in other projects. Secondly, the abstract outline play scenarios presented in this paper may be considered for use with other user groups/applications.

\section{ACKNOWLEDGMENTS}

We would like to give special thanks to the teaching staff, parents and children at Woodland school, St. Elizabeth's School, Middleton School, and Bentfield Primary School.

We would also like to thank the IROMEC partners for their contribution in the development of the scenarios, and the anonymous reviewers for their constructive and helpful comments.

\section{REFERENCES}

[1] P. Marti, A. Rullo, H. H. Lund, and J. Nielsen, "Playing with emotions," presented at the annual conference of the European association of cognitive ergonomics, ECCE, York, UK, 2004.
[2] P. Marti, A. Pollini, and A. Rullo, "Experiencing the flow: design issues in human-robot interaction," in Smart Objects and ambient Intelligence, sOc and Eusai Conference. Grenoble, France, 2005.

[3] P. Marti, A. Pollini, A. Rullo, and T. Shibata, "Engaging with artificial pets," presented at Annual Conference of the European Association of Cognitive Ergonomics, EACE 2005.

[4] D. Stiehl, J. Lieberman, C. Breazeal, L. Basel, R. Cooper, and H. Knight, "The Huggable: A Therapeutic Robotic Companion for Relational, Affective Touch," presented at IEEE Consumer Communications and Networking Conference, Las Vegas, NV, USA, 2006.

[5] K. Dautenhahn and A. Billard, "Games children with autism can play with robota, a humanoid robotic doll," in Universal Access and Assistive Technology, S. Keates, P. M. Langdon, P. Clarkson, and P. Robinson, Eds. London: Springer-Verlag, 2002, pp. 179190.

[6] B. Robins, K. Dautenhahn, R. te Boekhorst, and A. Billard, "Effects of repeated exposure of a humanoid robot on children with autism," in Designing a More Inclusive World, S. Keates, J. Clarkson, P. Langdon, and P. Robinson, Eds. London: SpringerVerlag, 2004, pp. 225-236.

[7] B. Robins, P. Dickerson, P. Stribling, and K. Dautenhahn, "Robotmediated joint attention in children with autism: A case study in a robot human interaction," Interaction studies: Social Behaviour and Communication in Biological and Artificial Systems, vol. 5, pp. 161-198, 2004.

[8] B. Robins, K. Dautenhahn, R. te Boekhorst, and A. Billard, "Robotic assistants in therapy and education of children with autism: Can a small humanoid robot help encourage social interaction skills?," in Universal Access in the Information Society (UAIS): Springer-Verlag, 2005.

[9] B. Robins, P. Dickerson, and K. Dautenhahn, "Robots as embodied beings - Interactionally sensitive body movements in interactions among autistic children and a robot," presented at 14th IEEE International Workshop on Robot and Human Interactive Communication - RO-MAN '05, Nashville, USA, 2005.

[10] J. M. Carroll, Scenario-based Design: Envisioning Work and Technology in System Development New York: Wiley, 1995.

[11] M. B. Rosson and J. M. Carroll, "Scenario-Based Design," in The Human-Computer Interaction Handbook: Fundamentals, Evolving Technologies and Emerging Applications, vol. Chapter 53, J. Jacko and A. Sears, Eds.: Lawrence Erlbaum Associates, 2002, pp. 1032 1050 .

[12] L. McMahon, The handbook of play therapy. London: Tavistock/Routledge, 1992.

[13] K. Rubin, "The play observation scale (POS)," University of Maryland 2001.

[14] J. W. Santrock, Life-Span development, 10th ed. New York: McGraw Hill, 2006.

[15] F.R. Volkmar, Handbook of Autism and Pervasive Developmental Disorders, vol. 1: John Wiley \& Sons, 2005.

[16] A. Rizzo, P. Marti, F. Decortis, C. Moderini, and J. Rutgers, "The Design of POGO Story World," in Cognitive Task Design, E. Hollnagel, Ed. London: Earlbaum, 2003.

[17] I. Werry, K. Dautenhahn, and W. Harwin. Evaluating the response of children with autism to a robot. in RESNA 2001 Annual Conference, Rehabilitation Engineering and Assistive Technology 2001. Reno, Nevada, USA: Resna Press, Arlington.

[18] I. Werry, K. Dautenhahn, and W. Harwin. Investigating a robot as a therapy partner for children with autism. in European Conference for the Advancement of Assistive Technology 2001. Ljubljana - Slovenia.

[19] K. Blotcher and R. Picard, "Affective social quest," in Socially Intelligent Agents - Creating Relationships with Computers and Robots, K. Dautenhahn, A. Bond, L. Cañamero, and B. Edmonds, Eds.: Kluwer Academic Publishers, 2002, pp. 133-140.

[20] S. Weir and R. Emanuel, "Using logo to catalyse communication in an autistic child," University of Edinburgh 15, 1976.

[21] D. Strickland, "A virtual reality application with autistic children," Presence: Teleoperators and Virtual Environment, vol. 5, pp. 319 329, 1996. 
[22] D. Strickland, "Virtual reality for the treatment of autism," in Virtual Reality in Neuro-Psyco-Physiology, G. Riva, Ed. Amsterdam: IOS Press, 1998.

[23] F. Michaud and F. Théberge-Turmel, "Mobile robotic toys and autism: Observations of interactions," in Socially Intelligent Agents - Creating Relationships with Computers and Robots, Boston and Dordrecht, Eds. London: Kluwer Academic Publishers, 2002, pp. 125-132.

[24] F. Michaud, A. Duquette, and I. Nadeau, "Characteristics of mobile robotics toys for children with pervasive developmental disorders," presented at IEEE International Conference on Systems, Man and Cybernetics, 2003.

[25] A. Duquette, H. Mercier, and F. Michaud, "Investigating the Use of a Mobile Robotic Toy as an Imitation Agent for Children with Autism," presented at International Conference on Epigenetic Robotics: Modeling Cognitive Development in Robotic Systems, Paris, France, 2006.

[26] F. Michaud, T. Salter, A. Duquette, H. Mercier, H. Larouche, and F. Larose, "Assistive technologies and child-robot interaction," presented at Proceedings American Association for Artificial Intelligence Spring Symposium on Multidisciplinary Collaboration for Socially Assistive Robotics, Stanford, 2007.

[27] F. Michaud, H. Larouche, F. Larose, T. Salter, A. Duquette, and H. Mercier, "Mobile robots engaging children in learning," in Canadian Medical and Biological Engineering Conference. Toronto, 2007.

[28] K. Dautenhahn, I. Werry, J. Rae, P. Dickerson, P. Stribling, and B. Ogden, "Robotic Playmates: Analysing Interactive Competencies of Children with Autism Playing with a Mobile Robot," in Socially Intelligent Agents - Creating Relationships with Computers and Robots, K. Dautenhahn, A. Bond, L. Canamero, and B. Edmonds, Eds. Boston: Kluwer Academic Publishers, 2002, pp. 117-124.

[29] K. Dautenhahn and I. Werry, "Towards interactive robots in autism therapy: Background, motivation and challenges," Pragmatics and Cognition, vol. 12, pp. 1-35, 2004.

[30] I. Werry, K. Dautenhahn, B. Ogden, and W. Harwin, "Can social interaction skills be taught by a social agent? The role of a robotic mediator in autism therapy," presented at The Fourth International Conference on Cognitive Technology: Instruments of Mind, Berlin 2001.

[31] M. Davis, B. Robins, K. Dautenhahn, C. Nehaniv, and C. Powell, "A comparison of interactive and robotic systems in therapy and education for children with autism," presented at Assistive Technology, from Virtuality to Reality, Lille, France, 2005.

[32] A. J. Hornof and A. Cavender, "EyeDraw: Enabling Children with Severe Motor Impairments to Draw with Their Eyes," presented at SIGCHI conference on Human factors in computing systems, 2005.

[33] C. E. Lathan and S. Malley, "Development of a New Robotic Interface for Telerehabilitation," presented at Proceedings of the 2001 EC/NSF workshop on Universal accessibility of ubiquitous computing: providing for the elderly, Portugal, 2001.

[34] S J. Schulmeister, C. Wiberg, K. Adams, N. Harbottle, and A. Cook, "Robot Assisted Play for Children with disabilities," presented at 29th Annual Resna Conference Proceedings, 2006.

[35] A. Cook, K. Howery, J. Gu, and M. Meng, "Robot enhanced interaction and learning for children with profound physical disabilities," Technology and disability, vol. 13, pp. 1-8, 2000.

[36] A. M. Cook, B. Bentz, N. Harbottle, C. Lynch, and B. Miller, "School-based use of a robotic arm system by children with disabilities," Neural Systems and Rehabilitation Engineering, IEEE Transactions, vol. 13, pp. 452- 460, 2005.

[37] G. Kronreif, B. Prazak, S. Mina, M. Kornfeld, M. Meindl, and M. Fürst, "Playrob - robot-assisted playing for children with severe physical disabilities," presented at 2005 IEEE, 9th International Conference on Rehabilitation Robotics, Chicago, IL, USA, 2005.

[38] H. H. Lund, P. Marti, and V. Palma, "Educational Robotics: Manipulative Technologies for Cognitive Rehabilitation," presented at Ninth international symposium On Artificial life and robotics (AROB 9th '04), Oita, JAPAN, 2004.
[39] H. H. Lund and P. Marti, "Designing Manipulative Technologies for Children with Different Abilities," Artificial Life \& Robotics, vol. 9, 2005.

[40] H. Kozima, C. Nakagawa, and H. Yano, "Can a robot empathize with people?," International Journal Artificial Life and Robotics, vol. 8, pp. 83-88, 2004

[41] H. Kozima, C. Nakagawa, and H. Yano, "Using Robots for the Study of Human Social Development," in AAAI Spring Symposium, 2005, pp. 111-114.

[42] H. Kozima, C. Nakagawa, and Y. Yasuda, "Designing and observing human-robot interactions for the study of social development and its disorders," presented at 6th IEEE International Symposium on Computational Intelligence in Robotics and Automation- CIRA 2005, 2005.

[43] F. Michaud and S. Caron, "Roball, the Rolling Robot," Autonomous Robots, vol. 12, pp. 211-222, 2002.

[44] H. Kozima and H. Yano, "A robot that learns to communicate with human caregivers," presented at First International Workshop on Epigenetic Robotics, 2001.

[45] H. Kozima and H. Yano, "Designing a robot for contingencydetection game," in Technical Report University of Hertfordshire, Report No 364 W.o.r.a.v.i.s.i.a. therapy, Editor. 2001.

[46] E. Ackermann, "Ambienti di gioco programmabili: cos'è possibile per un bambino di quattro anni?," Tecnologie Didattiche e Scienze Cognitive, vol. 27, pp. 48-56, 2002.

[47] H. Raffle, A. Parkes, and H. Ishii, "Beyond Record and Play. Backpacks: Tangible Modulators for kinetic Behavior," presented at CHI 2006, 2006.

[48] A. Chioccariello, S. Manca, and S. L., "Children's playful learning with a robotic construction kit " in Developing New Technologies for young children, Chapter 6, J. Siraj-Blatchford, Ed. UK Trentham Books Ltd., 2004

[49] A. Chioccariello, S. Manca, and L. Sarti, "Kit de construction de comportements," presented at Constructivismes: Usages et perspectives en education, Genève, Suisse 2001.

[50] A. Chioccariello, S. Manca, and L. Sarti, "La fabbrica dei robot," TD Tecnologie Didattiche, Menabò, 2002.

[51] H. H. Lund, T. Klitbo, and C. Jessen, "Playware technology for physically activating play," Artifical Life and Robotics Journal, vol. 9 , pp. 165-174, 2005 .

[52] B. Robins, N. Otero, E. Ferrari, and K. Dautenhahn, "Eliciting Requirements for a Robotic Toy for Children with Autism Results from User Panels," presented at RO-MAN07-International Symposium on Human and Robot Communication, 2007. 